\title{
IN SEARCH OF CREATIVITY: THOUGHTS ON A SOCIOLOGICAL EDUCATION
}

Thomas J. Cottle

Harvard University

\begin{abstract}
Although a child of a most rich and ecclectic intellectual background, sociology has all but isolated itself from the very tradition which gives it breath. This is visible in the pitiful representation of theory courses and the simultaneous surfeit of methodological passions or what might be called tool collecting. George Fomans has argued that the greatest danger of sociology is its insistence upon theoretical propositions of the ilk posited in structural functionalism. Insisting that these incomplete notions break down entirely in analysis, Homans points to Smelser's Social Change in the Industrial Revolution as an example of the inadequacy of this type of theory. Homans then advances the notion that men, not systems, make changes and live according to these changes which they have instituted.
\end{abstract}

I would disagree with Professor Homans. Although obviously incomplete at times, structural functionalism is not the evil of sociology. As Mills so often wrote, the evil is that sociologists are becoming so fettered by technique and hence, so removed from intellectualism and ideology, that they are unable to contribute anything to social theory except periodic vapid attacks on structural functionalism. I am not arguing that the Parsonian tradition has succeeded in accomplishing the quintessence of macro-theory. I am suggesting that the bureaucracy existing in the business of sociology is slowly but surely squelching creativity, ideology, and whatever else it is that produces new theoreticians. Perhaps the structural functional game will slow people down as so often happens after the introduction of bold and comprehensive macro-theory, but-the evil which has begun to fester is the ethos that eneourages immaculate

I would argue that one of our biggest problems is represented neither by the ubiquitous language of structural functionalism nor our failure to include men in our analyses. It is that we are now separated from our theoretical origins and traditions, separated from creative concerns, separated from intellectual pursuits, and that just as soon as a reconcilable settlement can be promoted, divorce proceedings will commence.

A second observation derives from this notion of a divorce from ideology. Specifically, I fear that in time, with the separation from ideas, there will come a spatial disengagement as well. Sociology then will lose its position in the social sciences and will go to live upstairs over business and law. But sociologists will resist this because these latter fields require at least a flirtatious intimacy with the public, an intimacy which presently frightens and frustrates the sociologists. Protected in the edifices of the social sciences, the sociologist can perpetuate his cult of mysterious information and besmirch the iconoclasts who publish more public documents. 
A recent issue of TRANS-Action printed a series of letters which once again portrayed the sociologist's dread of public consumption, indeed public success by fellow workers. Packard and Riesman are disenfranchised. Myrdal (although an economist) is in danger of losing his position in the cult - as if he cared - and the youth of the field wait with baited breath to learn of the fate of professors as they seek to disentangle Californian and Columbian cacaphony and free speech. In short, sociologists are in danger of becoming legitimated name callers and phenomena painters who perpetuate their own organizations of fraternalism, play their marketplace dramas, polish their star systems, and then, while waiting for the final consummation of the divorce, refuse to reorient their participation in a bureaucratic structure which they themselves have described so well for others. The seriousness of this bureaucracy, is that it grows, indeed metastasizes, upon the very source of sociology, the individual academic department.

Let me discuss three dangers which threaten to tarnish the Ph.D. luster. First is inflexibility. By inflexibility I mean the inability to see beyond one's own necessarily meager processes of data organization. Any form of reductionism must operate to lessen the possibility of perceiving the world with various sets of analytic eyes. In fact, if one believes too strongly in a theory or methodology, truth itself may be distorted in order that it fit pre-existing conceptualizations. When the sociologist becomes inflexible, science is dead, and only the most pitiful and unrepresentative data will remain behind.

The second danger of the bureaucratized sociologist is "closedness," really the reluctance to change or grow. One might say that inflexibility and closedness together comprise a kind of academic prejudice of which the public is unaware, but which the novitiate academician of ten misconstrues as sacred confidence and trust.

The final danger is a mixture of insufficient creativity and courage or what might be described as a generalized fear of alienation. Marvelously colorful and strong, these words mean simply that contemporary sociologists, as evidenced in their training programs, discourage creativity, individuality, uniqueness and even aloneness. Somehow, status differentials, and problems of expertise which exist naturally, in all universities, are coupled with the fact that up until the present time, too few have taken the student seriously. (For that matter it has been only recently that significant members of the society take university faculties seriously). The result of all of this is a belief system which discourages questioning, wondering and initiative. The graduate program apprenticeship, which no one denies is essential (or do they?), has come to be swathed in a semi-religious aura. Its very presence has instigated a series of experiences in which the student perceives his mentor as some gigantic cosmic force, and his mentor's publications as addenda to the scriptures, if not rediscovered apocryphal writings. Thus, soon after graduate incarceration, students gradually forfeit their "right" to creative thinking, perhaps in order to preserve time for learning the questionable tools of the business. 
The notion of courageous thought is perhaps anachronistic. We have moved past the time when ideas needed to conform to societal or religious expectations, and yet, the stiffening bureaucratization of sociology seems to be producing terribly diffident products. Furthermore, there arises a conservative, or at least a Calvinist ethic, which clamors for disciplined research and spurns the abandoned styles of more audacious reasoning, all of which produces miasmas of journal articles, compendia of information, occasional contributions to knowledge but only rare acts of competent creativity. The hideous aspect of all of this is the speed with which students are socialized into believing in the ethic, in the inevitability of the system, and the subsequent need to support it.

In his reluctance to assume an intellectual position in which he genuinely believes, the sociologist tightens his hold on the system's sanitized apron strings, and thereby precludes any possible separation from the fraternity. Those who do break away, either by token of their peculiar talents or their appeal to a public hearing, are rarely readmitted to the fold and proclaimed outcasts, publicists, popularists or heaven forbid, status seekers. There is even a contention that a work cannot have public acceptance and still be meritorious. But more important, sociologists seem unwilling to assume a public stance, or more importantly, a political stance. It is shocking to find that so few sociologists are budged by the affluence of contemporary social dynamics. Few write, fewer march, but grant applications multiply by the hour, and the number of scholarly.journals increases even as we breathe. But despicably, few changes are attempted within the bureaucracy. Sociologists are not - alienated because they have made such a silent contribution and because they have begun to relinquish their ties with the only world which can give meaning and principle to their efforts, the world of ideas.

In short, sociology may gradually become a rather uninteresting business, offering terribly low profit rates and minimal gratification, unless it either reaffirms its status among the so-called fellowship of educated men and women, or involves itself with the socio-political dynamics which it describes. Hopefully, it will do both.

A major source of this incipient dilemma is the present state of graduate programs. What I find most disagreeable and frightening is the notion that human brains are conceived of as sculptured little bags into which previously educated cherubs drop divine tools. From the point of view of bureaucratic stability, there is no better way of assuring perpetuation of the system than by tool-bag filling, but no one must utter the belief that this will suffice for education, much less scholarship. I have observed the absence of creative thinking in graduate programs (both on the part of planners and students) as well as the almost laughable projects presented to students as creative exercises.

To illustrate, some examinations presume to ask students to design on the spot, a major study in the course of one half hour. This is supposed to be some valuable measure of creative swiftness. Yet, this 
is an utterly absurd measure of anything, for there is absolutely no resemblance between this task and one of a so-called creative nature, much less one which adequately represents reality. Other types of examination questions are creeping slowly to the level of intelligence found in medical school examinations, to wit, what is the length of a cochlea? and estimate the weight of a trachea.

Still another example is the examination in which students are asked to read data tables. Note, interpretation of the data is not required, merely a check that one can understand the now infamous blueprints of the sociological world. All of these tasks are no doubt essential in the techniques which they advance, but none belong on preliminary examinations and none deserve so much public affirmation and practice.

A similar form of academic ritual is the business of data collection. One is not truly initiated until he has returned from the "field" with anything that can be transformed no matter what the degree of distortion, into elegant numbers, thence undergo majestic computerization. The psychosexual connotations of the sociologist's fixation on hard data is a dissertation into itself. Our concern here, however, is with the pernicious effect that data collecting ceremonies have on potential creative thinking and the still pure imagination. Briefly, the sociologist's emphasis on technique and facility has obliterated not only the bounty of society as a subject of study, but the spark of education and intellectualism which should be our duty to maintain. If we're not careful, we will gradually become so transfixed by our rendering of scales and finger exercises, that we will dismiss all our feelings about the real music that lies quietly beyond.

Up to now, I have offered four major points:

1. Sociology is gradually divorcing itself from a so-called history of ideas.

2. The cultivation of a mystical information society has been misconstrued as scholarship and knowledge. Moreover, students who write in part for the utility of public consumption, are met with envy, hostility and implicit excommunication for they have disobeyed "the trust".

3. Flexibility, openness and creativity do not at all dominate sociological thinking. Methodology, experimentation and conservatism dominate instead.

4. The swift approach of bureaucratic sterility comes as a function of uncreative, timid, and indeed, anti-intellectual training programs which emphasize tool collection, colleague worshipping, and even worse, the depreciation of explorative thought and fearless pursuit.

One result of all this necessarily will be a generation of young men and women myopically staring at the world about them and lamenting the passing of their earlier courage to assume any stance qua the society of which they profess having some knowledge. When, for example, will 
sociologists do anything other than sophomoric post facto analyses of free speech movements, civil rights demonstrations and riots? When will sociologists feel a need to usurp often glib, often prolix and usually improperly trained journalists and college students as the spokesmen of social change? When will the secretive tones of silent understanding become dissatisfying and openly corrupt? Not ironically, grantsmanship, data hardening, empire building, table making and the undaunted tool game will make the sociologist obsolete even before the inception of puberty. ( $I$ would suggest that the computer presently is functioning as the great adjudicator of these very same inquitous[sic] devices.)

The problem then, is that the professionalization of the sociologist may prohibit any consequential contribution to the study of a changing society and participation in the direction of this change or indeed, a competent reporting of it. Right at this moment, sociological leadership would be a case of the bland leading the blind. And yet, by isolating the source of this blandness in graduate education, there still may be time to initiate a little rebellion in sociology by way of preparing for and anticipating its adolescence.

My plea to educators is exactly the position expressed and extolled by Whitehead, namely the maintenance of any and all educative resources which encourage imagination and creativity. We must do everything to reinforce individualistic and collective exploration and discovery in those students who choose this most exciting route. This approach can be aided by incorporating student's contributions in curriculum planning sessions, small discussion groups, and other adjustments of this nature, but the major transformation will have to come from a shift in contemporary philosophies of sociological education. If the administrator's goal is merely to produce competent sociologists, I feel his task is relatively simple and conspicuously fruitless. If sociologists want automated technicians no more gifted in their line than the burgeoning group of mindless medicos, then I would suggest that absolutely no educative changes be made. If, on the other hand, sociologists might welcome cohorts of expansive, articulate, aware people who might themselves welcome the task of carrying sociology beyond a bepimpled adolescence to creative and contributory adulthood, then serious changes will have to be made.

The major change or maturation will have to come in the philosophy of teaching, again with the idea that every possible opportunity to encourage creativity and belief in one's ability to be creative or at least innovative, must be exploited. I underscore philosophy of teaching rather than refer to any pedagogic devices because I do not believe that change in the so-called structure of education automatically produces serious effects. Small group seminars, private tutorial sessions or even incestuous proximity of teachers and students, (relationships incidentally, about which students are so ambivalent) are no better than that archaic remain known as the lecture, if creativity is not being stressed. In fact, autocratic tool pushers will be even more effective in small group environments than they are now in mob size lecture proceedings. It is foolish to believe that the profound experience of hearing Tillich, 
Arendt, Shils, Bellow or Bettelheim in lecture, is "less valuable" than an intimate involvement or delightfully slick relationship with a tool pusher. Information can always be gotten, but exposure to the largesse, elegance, expansiveness, depth and fun of the creative mind is quite rare.

I would suggest a program which in its first year urges the student to study society without either theoretical or methodological assistance. I would ask him to paint society, to write about it, to touch and smell and feel it. I would let the student, unfettered by any prior intellectual predispositions, predelections or contrivances, study human institutions, groups, roles or whatever, in any way he chooses. Let him and her just get a taste of the melodic line before we shove the burden of harmony, counterpoint and solfège his or her way. After a year, and hopefully by now accepting and valuing the impulse of creative investigation, the student should be rady for a heavy dosage of theory and technique. Now he should be able to approach preliminary exercises with a modicum of courage as well as with a beginning feeling of competency. After a couple of years, the student might end his apprenticeship with his individual research to which he brings not only his tools and awareness of information, but an excitement with the creative process which once dominated his earl.y months, and which should now influence the approach he takes to his chosen topic as well as to his total iffe cycle.

Professor Jacob Getiels often rocalls Stanley Hall's belief that the first six years of a child's life are as significant for him as were the first six days for the creation of the world. Education is but one of the possible second chance opportunities for restructuring some of these first six years. The first months of graduate education greatly resemble those first six years in their contribution to the shaping of the intellect and outiook of the sociologist. The danger is that too much can be ruinesd tco soon.

An illustration of this sort of premature ruination is the often unnecessarily traumatic confrontation with statistics. Apart from the fact that many social scientists tremble from the sight of any kind of numbers (which may be a good sign), statistics frequently remain a meaningless ceremony in the educative experience. It is of ten the only required course in the entire program even though it may be taught with a "you just gotta have this stuff" attitude. For the student, the ordeal of learning statistics is a most foolish encounter because he always undergoes it before it could possibly have any meaning. One may be relatively sure that in undertaking his own societal investigation, the student most probably will reach that ignominious day when he quietly and reluctantly confesses his need for statistical training. (And, if he never reaches this day, perhaps statistics should be dropped from the list of his requirements altogether).

This will be the case for the acquisition of most all the essential and required techniques. There is added richness in the awareness and recognition of methodological technologies, but they must be couched 
in even a minimal form of contextual meaning. Creativity, however, is but a soft and delicate wisp, too often crushed by the rains of marching chi squares, regressions and factor scores. Preserving this creative wisp is one gargantuan chore, but the profits are potentially inestimable.

I urge changes in undergraduate and graduate curricula because of the growing need for sociologists to become competent chroniclers as well as institutional analysts. The study of bureaucracies and change cannot be adequately treated until sociologists, the logical students of such phenomena, are themselves emancipated from their own limited perspectives which are, in part, a function of the sociological establishment. Until educative policies change, novelists will remain as the truly articulate students of society. I find this unfortunate because there is so much which fiction does not purport to describe or understand.

Many are fully aware of the situation I have tried to review, but so often they go about revolution in such ludicrous fashion. There is the case of a professor who wrote a memo to a student asking about what could be done to improve academic social relationships between faculty and students. How incidious the effects of bureaucratic management. and procedures! The intentions were so noble and good, but the means were ingeniously and almost comically self-defeating.

If sociologists are to make a contribution to knowledge (not just to the stores of existing information), they will have to shift their temporal perspectives. They will have to reunite themselves with their marvelously ecclectic heritage on the one hand, and cultivate anticipatory research on the other. It may be worthwhile to substitute a bit of history for statistics and some childlike freedom in creativity for methodology, if only to break the highly developed present-oriented and self-aggrandizing framework emerging in the social sciences. Such a change may even function to re-awaken a political involvement on the part of sociologists. We are not irretrievably trapped in an era reifying technology, although literary style, research proposals, the discouragement of theoretical manuscripts and the insistence upon systematic sustenance often makes us believe that we are. The reification of technology from which we must soon extricate aurselves, not only impedes the growth of our field, it produces volumes of eternally outdated and frightfully uninteresting materials.

Finally, let me further destroy tradition by closing with a presentation of some data. Eighty five undergraduates (males and females from the University of Chicago) were asked to rank social science disciplines (nine in all) on three different scales: First, intellectual importance, appeal and esteem; second, as possible career choice; and third, as potential contribution to understanding and helping society. Sociology ranked lowest in the first category, second from lowest in the second category but second in category three. Thus, sociology was deemed by the respondents as lacking in esteem and intellectual significance, but nevertheless needed and looked to for assistance. 
Sociological education must learn from the arcane tenets of medical education and prevent further "technogenesis." In short, sociologists must not disenfranchise themselves by becoming stodgy and straightlaced. A little abandon and a touch of courage (chutzpah if you will) might do wonders for a business which now is frighteningly successful. 